\title{
First data on myiasis caused by Wohlfahrtia magnifica (Schiner, 1862) (Insecta: Diptera: Sarcophagidae) in Calabria, southern Italy ${ }^{1}$
}

\author{
Teresa Bonacci ${ }^{2}$, Silvia Greco ${ }^{2}$, Daniel Whitmore ${ }^{3}$, and Ugo Curcio ${ }^{4}$
}

\begin{abstract}
Wohlfahrtia magnifica (Schiner, 1862) (Diptera: Sarcophagidae) is the main species responsible for traumatic myiasis in humans and warm-blooded vertebrates in the Mediterranean Basin, Central Europe and Central Asia. Despite recent reports, data on obligatory wound myiasis in domestic and farmed animals in Italy are still scarce. The case of wohlfahrtiosis presented here is the first reported from Calabria (southern Italy). Larvae of W. magnifica were found in an epidermoid cyst located in the abdominothoracic area of a domestic dog. A total of 98 third instar larvae were removed from inside the cyst and either preserved in ethanol or reared to the adult stage. In Italy, as well as in other areas endemic to wohlfahrtiosis, data about the seasonality, local distribution and patterns of infestation of W. magnifica are very useful to veterinarians and farmers to understand infestation mechanisms and improve control strategies.
\end{abstract}

Key Words: wohlfahrtiosis, Wohlfahrtia magnifica, dog, Italy

Myiasis, as defined by Zumpt (1965), is an "infestation of live human and vertebrate animals with dipterous larvae, which, at least for a certain period, feed on the host's dead or living tissue, liquid body-substances, or ingested food". These infestations can be caused by many species across several different families of Diptera, but larvae of Calliphoridae, Sarcophagidae and Muscidae are the main causes of traumatic myiasis in humans and domestic animals (Zumpt 1965, Hall and Wall 1995, Hall 1997, Hall and Farkas 2000, Sinha 2012). The obligate parasitic sarcophagid Wohlfahrtia magnifica (Schiner, 1862) is one of the most renowned agents of myiasis in the Old World, where it is known to attack both humans and domestic animals (Portschinsky 1916, Hall and Farkas 2000 and references therein). It is most common in the warmer parts of the Palaearctic Region from the Mediterranean Basin, Central Europe and Asia Minor to Central Asia and China (Ruíz-Martínez and Lecqlerq 1994, Pape 1996, Sotiraki et al. 2010). In Italy, cases of myiasis caused by W. magnifica have been reported from the regions Abruzzo, Campania, Lazio, Molise, Tuscany, Sardinia and Sicily (Ambrosi and Principato 1994, Iori et al. 1999, Panu et al. 2000, Gaglio et al. 2011, Giangaspero et al. 2011); Venturi (1960)

\footnotetext{
${ }^{1}$ Submitted on November 7, 2013. Accepted on November 9, 2013. Final revisions received on November 22, 2013.

${ }^{2}$ DiBEST, Università della Calabria, 87036 Rende, Cosenza, Italy. Emails: teresa.bonacci@unical.it (TB), silviettagreco@gmail.com (SG).

${ }^{3}$ Corresponding author. Department of Life Sciences, Natural History Museum, Cromwell Road, London, SW7 5BD, England, UK. E-mail: d.whitmore@nhm.ac.uk

${ }^{4}$ Corso Italia 162, Montalto Uffugo, Cosenza, Italy. E-mail: ugocurcio@tiscalinet.it
}

DOI: 10.9784/LEB1(4)Bonacci.02 Electronically available on November 27, 2013. Mailed on December 28, 2013. 
found adult specimens from Abruzzo, Campania and Lazio in the Bezzi collection. According to Farkas (2006) and Farkas et al. (2009), dogs have acquired an important role in the spread of wohlfahrtiosis in Morocco and Hungary.

In July 2012, during a veterinary examination in a private clinic, an epidermoid cyst (diameter $10 \mathrm{~cm}$ ), infested by several fly larvae (Figure 1), was found in the abdominothoracic area of a 10 year old female dog. The dog came from a private home in Montalto Uffugo (39 $25^{\prime} 26.81^{\prime \prime} \mathrm{N} 16^{\circ} 13^{\prime} 19.22^{\prime \prime} \mathrm{E}, 177 \mathrm{~m}$ ) in the province of Cosenza (Calabria, southern Italy). The house has a private garden and is not in close proximity of any sheep pastures or sheds. After clinical examination of the case, the cyst was surgically removed and general administration of antibiotics was carried out. A total of 98 third instar larvae were removed from inside the cyst. Ten larvae were isolated and stored in $90 \%$ ethanol, while the remaining third instars were reared in the laboratory to the adult stage. Both the larvae and the adults were identified as Wohlfahrtia magnifica (Figure 2). Adults were compared to specimens held in the Natural History Museum of Denmark and to illustrations in Rohdendorf (1956); larvae were compared to illustrations in Lehrer and Fromunda (1986). All examined larvae and adults are deposited, respectively, in the 'Tullia Zetto larval collection' (TZC) and the collection of Prof. Pietro Brandmayr (PBC) (both DiBEST Department, University of Calabria, Cosenza, Italy). Digital photographs were taken with a Sony Super Steadyshot DSC-H2 digital camera.

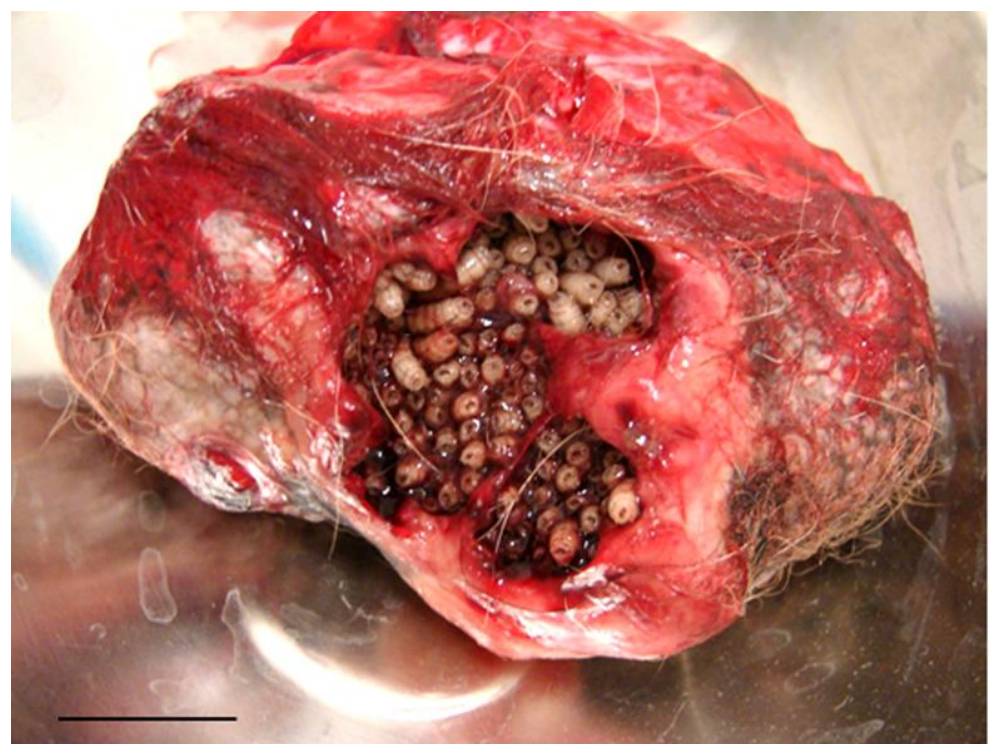

Figure 1. Severe myiasis in epidermoid cyst of a dog caused by larvae of Wohlfahrtia magnifica (Schiner, 1862) in Montalto Uffugo, southern Italy (scale bar: $2 \mathrm{~cm}$ ). 

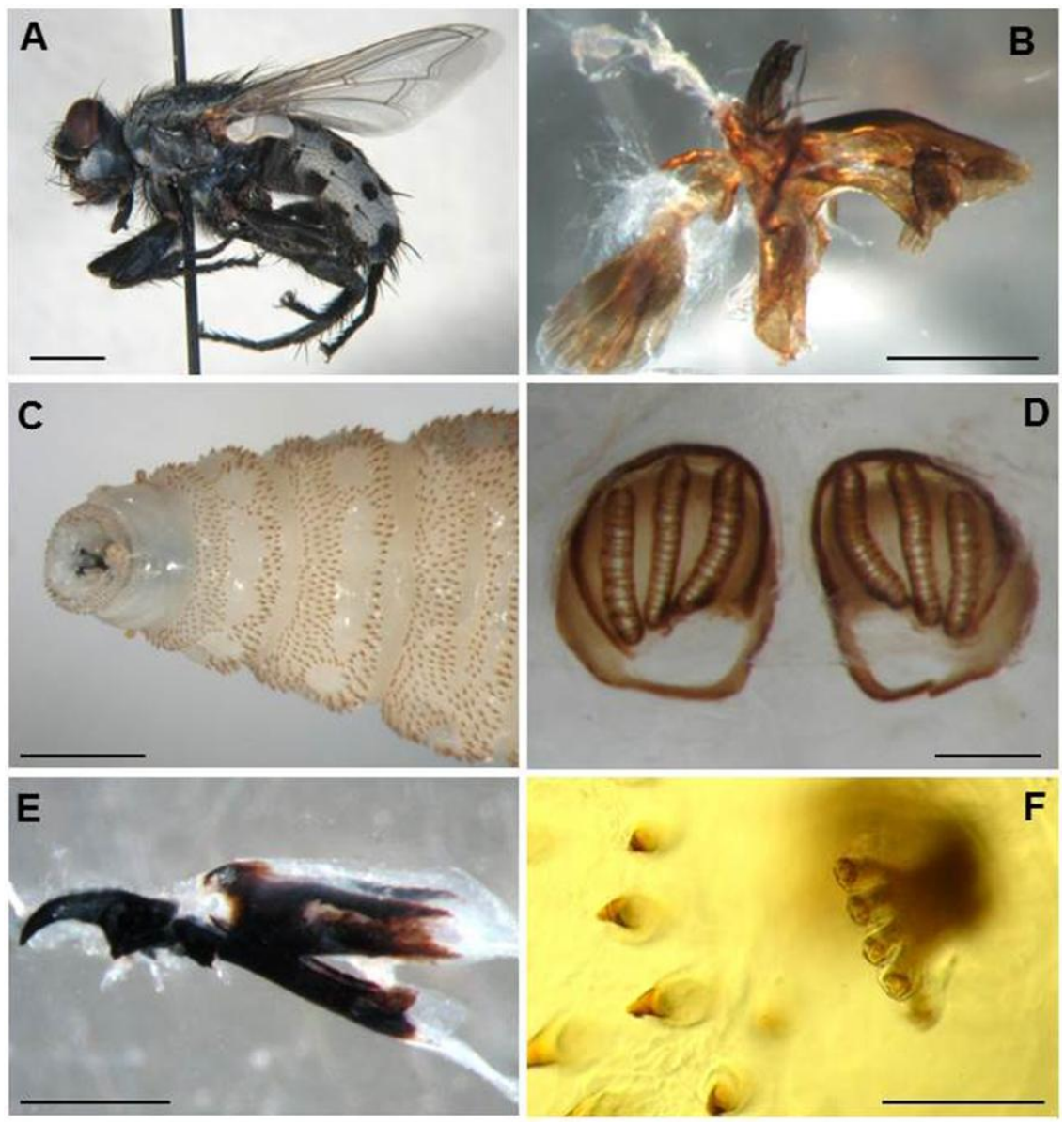

Figure 2. Wohlfahrtia magnifica (Schiner, 1862). A. Habitus of male (scale bar: $2 \mathrm{~mm}$ ). B. Male genitalia (scale bar: $0.5 \mathrm{~mm}$ ). C. Pseudocephalon and thoracic segments of third instar larva (scale bar: $1 \mathrm{~mm}$ ). D. Posterior spiracles of third instar larva (scale bar: 0.25 $\mathrm{mm}$ ). E. Cephalopharyngeal skeleton of third instar larva (scale bar: $0.5 \mathrm{~mm}$ ). F. Anterior spiracles and spines of third instar larva (scale bar: $0.15 \mathrm{~mm}$ ).

In Italy, data on infestations by W. magnifica are scarce. Recently, cases in dogs, sheep and goats have been reported for some Italian regions (Gaglio et al. 2011, Giangaspero et al. 2011), where the occurrence of wohlfahrtiosis is apparently endemic. The present finding of $W$. magnifica larvae in an epidermoid cyst of a dog represents the first record of wohlfahrtiosis from Calabria (southern peninsular Italy). Frequently, larvae of W. magnifica infest natural orifices (Sotiraki et al. 2010), and the gravid females are attracted by chemicals contained in vaginal discharges or urine (see Hall 1995, Farkas et al. 
2009). In this case, the larvae probably infested the wound tissue of the cyst after it had burst.

In conclusion, and as emphasized by Giangaspero et al. (2011), accurate inspections on myiasis caused by larvae of W. magnifica are needed in order to map its occurrence and develop effective control measures, e.g. through use of vaccines or odour-baited traps for control of the adult fly populations (see RuízMartínez and Leclercq 1994, Hall 1995, Hall and Farkas 2000, Sotiraki et al. 2010). Knowledge of the distribution and phenology of the species is equally important, yet data are still extremely fragmentary. More in general, accurate and comprehensive information on the distribution of species of medical and veterinary importance is lacking in Italy, and making 'infestation maps' available for veterinary interventions as well as for ecological and biological studies should be a priority objective.

\section{Acknowledgements}

We thank Dr. Krzysztof Szpila (Nicolaus Copernicus University, Toruń, Poland) for confirming our identification of the larvae of Wohlfahrtia magnifica. Thanks to Dr. Martin Hall (Natural History Museum, London) and three anonymous reviewers for their critical review of a previous draft of the manuscript.

\section{Literature Cited}

Ambrosi, M. and M. Principato. 1994. Outbreak of vaginomyiasis by Wohlfartia [sic] magnifica in grazing cattle in Central Italy. Parassitologia 36(Supplemento 1):5.

Farkas, R. 2006. Traumatic myiasis of dogs caused by Wohlfahrtia magnifica (Diptera: Sarcophagidae). Folia Veterinaria 50(3):41-43. http://dx.doi.org/10.1111/j.13652915.2008.00772.x

Farkas, R., M. J. R. Hall, A. K. Bouzagou, Y. Lhor and K. Khallaayoune. 2009. Traumatic myiasis in dogs caused by Wohlfahrtia magnifica and its importance in the epidemiology of wohlfahrtiosis of livestock. Medical and Veterinary Entomology 23(Supplement 1):80-85.

Gaglio, G., E. Brianti, S. Abbene and S. Giannetto. 2011. Genital myiasis by Wohlfahrtia magnifica (Diptera, Sarcophagidae) in Sicily (Italy). Parasitology Research 109:1471-1474. http://dx.doi.org/10.1007/s00436-011-2431-3

Giangaspero, A., D. Traversa, R. Trentini, A. Scala and D. Otranto. 2011. Traumatic myiasis by Wohlfahrtia magnifica in Italy. Veterinary Parasitology 175:109-112. http://dx.doi.org/10.1016/j.vetpar.2010.09.028

Hall, M. J. R. 1995. Trapping the flies that cause myiasis: Their responses to host-stimuli. Annals of Tropical and Medical Parasitology 89:333-357.

Hall, M. J. R. 1997. Traumatic myiasis of sheep in Europe: a review. Parassitologia 39(4):409-413.

Hall, M. J. R. and R. Farkas. 2000. Traumatic myiasis of humans and animals. pp. 751-768. In, L. Papp and B. Darvas (Editors). Contributions to a Manual of Palaearctic Diptera. Volume 1: General and Applied Dipterology. Science Herald. Budapest, Hungary. 978 pp.

Hall, M. J. R. and R. Wall. 1995. Myiasis of humans and domestic animals. pp. 257-334. In, J. R. Baker, R. Muller and D. Rollinson (Editors). Advances in Parasitology. Volume 35. Academic Press. London, England, UK. 387 pp.

Iori, A., B. Zechini, L. Cordier, E. Luongo, G. Pontuale and S. Persichino. 1999. A case of myiasis in man due to Wohlfahrtia magnifica (Schiner) recorded near Rome. Parassitologia 41(4):583585.

Lehrer, A. Z. and V. Fromunda. 1986. Le développement larvaire du diptère myiasigène Wohlfahrtia magnifica (Schiner) (Diptera, Sarcophagidae). Bulletins et Annales de la Société royale belge d'Entomologie 122:129-136. 
Panu, F., G. Cabras, C. Contini and D. Onnis. 2000. Human auricolar myiasis caused by Wohlfartia [sic] magnifica (Schiner) (Diptera: Sarcophagidae): First case found in Sardinia. Journal of Laryngology and Otology 114(6):450-452. http://dx.doi.org/10.1258/0022215001905814

Pape, T. 1996. Catalogue of the Sarcophagidae of the world (Insecta: Diptera). Memoirs on Entomology, International 8:1-558.

Portschinsky, J. A. 1916. Wohlfahrtia magnifica, Schin., and allied Russian species. The biology of this fly and its importance to man and domestic animals. Memoirs of the Bureau of Entomology Scientific Committee Central Board of Land Administration and Agriculture Petrograd 11:1108.

Rohdendorf, B. B. 1956. Palaärktischen Arten der Gattung Wohlfahrtia B. B. (Diptera, Sarcophagidae). Entomologicheskoe Obozrenie 35:201-229. [In Russian with German subtitle.]

Ruíz-Martínez, I. and M. Leclercq. 1994. Data on distribution of screwworm fly Wohlfahrtia magnifica (Schiner) in Southwestern Europe (Diptera: Sarcophagidae). Notes fauniques de Gembloux 28:53-60.

Sinha, S. K. 2012. Myiasis in domestic animals: new records of calyptrate Diptera. Journal of Parasitic Diseases 6(2):277-279. http://dx.doi.org/10.1007/s12639-012-0109-0

Sotiraki, S., R. Farkas and M. J. R. Hall. 2010. Fleshflies in the flesh: epidemiology, population genetics and control of outbreaks of traumatic myiasis in the Mediterranean Basin. Veterinary Parasitology 174:12-18. http://dx.doi.org/10.1016/j.vetpar.2010.08.010

Venturi, F. 1960. Sistematica e geonemia dei sarcofagidi (excl. Sarcophaga Meig. s. 1.) italiani (Diptera). Frustula Entomologica 2(7):1-124.

Zumpt, F. 1965. Myiasis in Man and Animals in the Old World: A Textbook for Physicians, Veterinarians and Zoologists. Butterworth. London, England, UK. 267 pp. 